\title{
Positron Emission Tomography Drug Production
}

National Cancer Institute

\section{Source}

National Cancer Institute. Positron Emission Tomography Drug Production. NCI

Thesaurus. Code C91403.

The activity of producing any reagents used in positron emission tomography (PET) diagnostic imaging, including radioactive nuclides, nonradioactive reagent, reagent kit etc. 